\title{
Peripheral trigeminal nerve field stimulation
}

\author{
Report of 6 cases
}

\author{
Alberto Feletti, M.D., Ph.D., ${ }^{1}$ Giannantonio Zanata Santi, M.D., ${ }^{1}$ \\ Francesco Sammartino, M.D., 1 Marzio Bevilacqua, M.D., 2 Piero Cisotto, M.D., 1 \\ and Pierluigi Longatti, M.D. ${ }^{1}$ \\ ${ }^{1}$ Department of Neurosurgery, Treviso Hospital, University of Padova; and ${ }^{2}$ Department of Anaesthesiology, \\ Pain Therapy Unit, Treviso Hospital, Treviso, Italy
}

\begin{abstract}
Object. Peripheral nerve field stimulation has been successfully used for many neuropathic syndromes. However, it has been reported as a treatment for trigeminal neuropathic pain or persistent idiopathic facial pain only in the recent years.

Methods. The authors present a review of the literature and their own series of 6 patients who were treated with peripheral nerve stimulation for facial neuropathic pain, reporting excellent pain relief and subsequent better social relations and quality of life.

Results. On average, pain scores in these patients decreased from 10 to 2.7 on the visual analog scale during a 17-month follow-up (range 0-32 months). The authors also observed the ability to decrease trigeminal pain with occipital nerve stimulation, clinically confirming the previously reported existence of a close anatomical connection between the trigeminal and occipital nerves (trigeminocervical nucleus).

Conclusions. Peripheral nerve field stimulation of the trigeminal and occipital nerves is a safe and effective treatment for trigeminal neuropathic pain and persistent idiopathic facial pain, when patients are strictly selected and electrodes are correctly placed under the hyperalgesia strip at the periphery of the allodynia region.
\end{abstract} (http://thejns.org/doi/abs/10.3171/2013.7.FOCUS13228)

\section{KEY WORDS - trigeminal neuropathic pain - persistent idiopathic facial pain peripheral nerve field stimulation • trigeminocervical nucleus • hyperalgesia}

$\mathrm{T}$ RIGEMINAL neuropathic pain is a constant, burning, aching, or cramping facial pain, which can be associated with areas of partial sensory deficit. ${ }^{6}$ Its intensity can fluctuate, eventually leading to chronic pain. Herpetic infection and traumatic or surgical injury to the facial branches of the fifth cranial nerve are among the most frequent causes of TNP. Persistent idiopathic facial pain (previously called atypical facial pain) is defined as a persistent facial pain that does not have the characteristics of cranial neuralgias and cannot be attributed to a different disorder. It is limited to one particular area on one side of the face at disease onset, is deep and poorly

Abbreviations used in this paper: PIFP = persistent idiopathic facial pain; PNFS = peripheral nerve field stimulation; PNS = peripheral nerve stimulation; TNP = trigeminal neuropathic pain; VAS = visual analog scale. localized, and is not associated with sensory loss or other neurological deficits, with no obvious structural abnormalities. Pain may be initiated by surgery or injury to the face, teeth, or gums, but it persists without any demonstrable local cause. . $^{8,10}$

First-line treatment includes anticonvulsant medications, baclofen, and opioids. Unfortunately, TNP and PIFP are often refractory to medical treatment. Moreover, patients frequently report side effects from medications as well as tolerance and dependence when opioid use is prolonged over time. Motor cortex stimulation and stereotactic trigeminal nucleotomy have been reported, with a success rate of $50 \%-70 \%$ of patients. ${ }^{16,20}$ More recently, PNS or PNFS have been used to treat TNP and PIFP, with promising results. ${ }^{3}$ We present a review of the literature about this technique (Table 1), adding our series of 6 patients (Table 2). 


\section{Case Reports}

Case 1

This 22-year-old woman presented to our outpatient clinic with a 3 -year history of left trigeminal neuralgia. The patient had undergone venous microvascular surgical decompression twice at another institution because of a misdiagnosis of typical trigeminal neuralgia. After surgery she still reported left facial pain, with thermal and mechanical static allodynia in the V1 and V2 territories, along with paresthesia and dysesthesia. Scar pain was also present in the territory of the greater and lesser occipital nerves, with left retroauricular hypesthesia. A left facial hemispasm induced frequent left eye blinking. Trigger points were detectable in the distribution of the $\mathrm{V} 1$ and V2 branches of the left trigeminal nerve and in the cephalic portion of the occipital scar. The patient reported $10 / 10$ pain on the VAS at admission. Her life was severely affected by facial pain. She had lost her job and had dramatically reduced her social activities.

After a 14-day trial of PNFS in the supraorbital, infraorbital, and greater occipital nerves, the patient returned to the clinic and reported significant improvement in pain relief and quality of life. She subsequently underwent implantation of 1 Axxess quadripolar and 1 Quatrode quadripolar percutaneous lead in the left V1 and V2 regions, and 1 Octrode octopolar percutaneous lead in the occipital region that were connected to a rechargeable pulse generator (Eon Mini; all equipment obtained from St. Jude Medical), which was implanted in the left subaxillary subcutaneous space. The implanted stimulator was programmed with a pulse width of $300 \mu \mathrm{sec}$ and a rate of $20 \mathrm{~Hz}$. The patient obtained excellent pain control (2/10 on the VAS). Fifteen months after surgery, the patient is not reporting significant pain, is considerably reducing drug intake, has found a new job, and has improved her social relationships.

\section{Case 2}

This 58-year-old man was involved in a crash trauma of the neurocranium and the facial skeleton 15 years prior to presentation, with right eye enucleation. He reported chronic right-sided facial pain in the V1 distribution and a more severe right-sided pain in the region of the greater and lesser occipital nerves. Pain was rated $9 / 10$ on the VAS and was poorly managed medically. On examination he had thermal and mechanical allodynia of the right frontoparietal region. Transcutaneous electrical nerve stimulation was applied in the right occipital and parietotemporal regions with a rate of $80 \mathrm{~Hz}$. Good pain control was obtained not only in the occipital region but also in the V1 distribution.

For this reason, after a 14-day trial of PNFS in the right greater occipital nerve he underwent implantation of 2 octopolar electrodes (Octad) that were connected to a Prime Advanced pulse generator (electrodes and pulse generator obtained from Medtronic, Inc.). The implanted stimulator was programmed with a pulse width of 450 $\mu$ sec and a rate of $80 \mathrm{~Hz}$, similarly to transcutaneous electrical nerve stimulation. Pain was successfully controlled, with a VAS score of 3/10 in both the occipital and V1 distributions. The patient reported an improvement of life quality. After a long period of unemployment, he found a job as a janitor, and he returned to his previous social activities. The system was removed 2 years later because of a foreign body giant cell-mediated granulomatous reaction, whose origin was not unquestionably defined. One year later, he underwent implantation of 2 octopolar percutaneous leads (St. Jude Medical) in the subcutaneous region of the greater and lesser occipital nerves; the leads were positioned mimicking a lotus flower shape to better cover the pain area (Fig. 1). Electrodes were connected to a rechargeable pulse generator (Eon Mini; St. Jude Medical), which was implanted in the right infraclavicular subcutaneous space. The implanted stimulator was programmed with a pulse width of $425 \mu \mathrm{sec}$ and a rate of $70 \mathrm{~Hz}$. The patient reported a significant decrease of pain (4/10 on the VAS), which was lasting as of the 32-month follow-up.

\section{Case 3}

This 41-year-old woman presented with a 4-year history of worsening pain in the V2 and V3 distribution bilaterally, with hypesthesia and paresthesia. Symptoms were more intense on the left side. The patient also reported impaired chewing movement. On examination she had thermal and mechanical static and dynamic allodynia. She reported a 10/10 pain on the VAS. The patient had been involved in a car accident 4 years prior to presentation to our clinic. She had multiple facial fractures, with right-sided LeFort 1, left-sided LeFort 1 and 2, inferior orbital rim, and nasal bone fractures, and detachment of several teeth. At that time, the fractures were stabilized with titanium plating, which had been removed 5 months later. During maxillofacial surgery, the surgeon described a laceration injury of the left infraorbital nerve. Severe facial pain appeared 4 months after the accident. Conservative treatments were not effective to reduce pain.

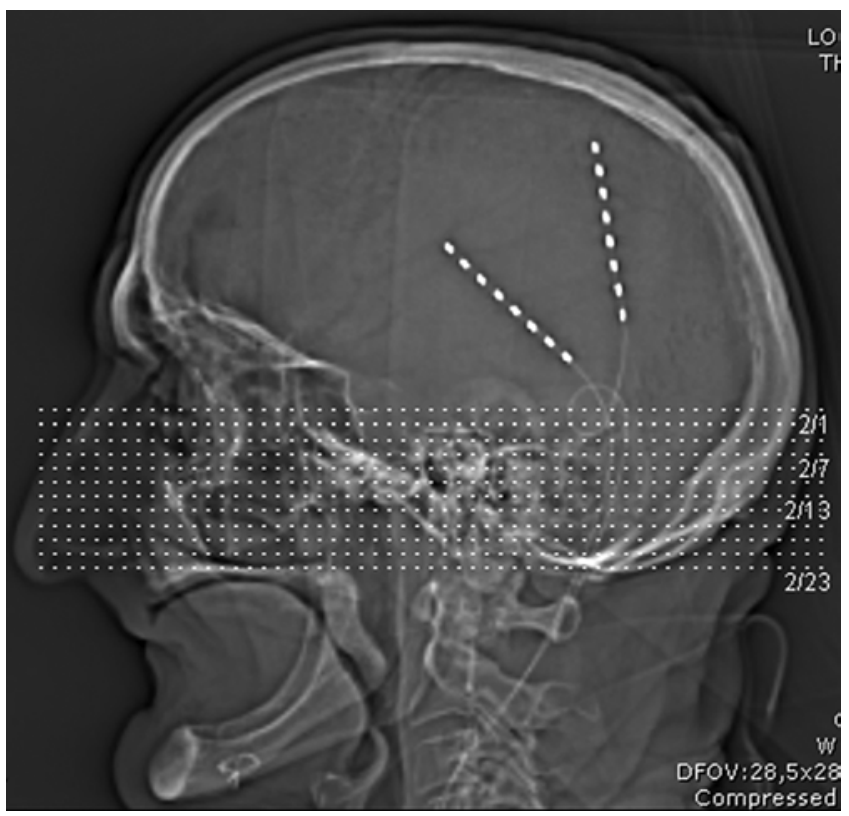

Fig. 1. Case 2. Lateral radiograph showing 2 octopolar leads in the occipital region. 


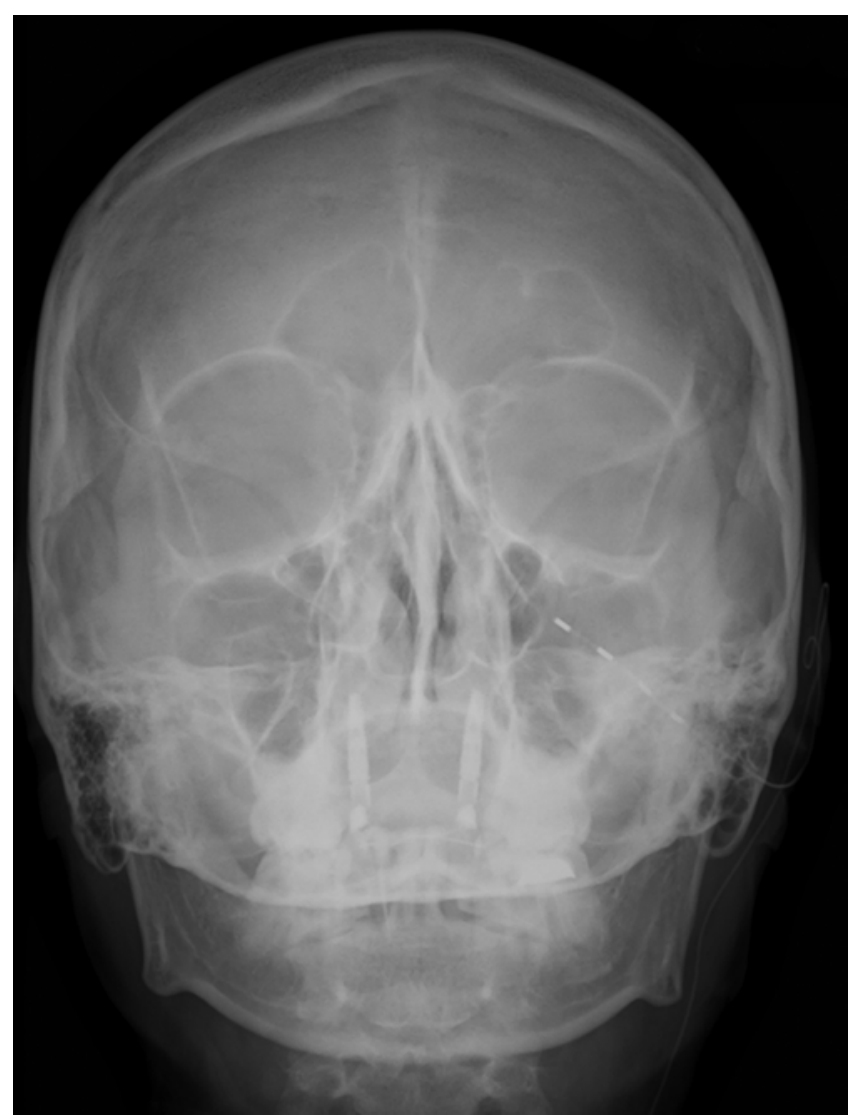

Fıg. 2. Case 3. Frontal radiograph showing a quadripolar lead in the left $\mathrm{V} 2$ region.

Analgesic block of the left infraorbital nerve with local anesthetics was successful.

After a 16-day trial of PNFS in the left infraorbital nerve, she underwent implantation of a quadripolar percutaneous lead (Axxess; St. Jude Medical) in the left V2 region that was connected to a rechargeable pulse generator (Eon Mini; St. Jude Medical). The implanted stimulator was placed in the left subaxillary subcutaneous space and was programmed with a pulse width of $350 \mu \mathrm{sec}$ and a rate of $16 \mathrm{~Hz}$ (Fig. 2). The patient reported a significant decrease of pain (VAS Score 0/10 on the left side and 5/10 on the right side). One year later she suffered a cervical spine trauma during a car collision. The electrode was distracted, with subsequent dysfunction. She underwent substitution of the electrode with a new Axxess quadripolar Quatrode percutaneous lead (St. Jude Medical). The pulse width was set at $300 \mu \mathrm{sec}$ and a rate of $16 \mathrm{~Hz}$. At the 19 -month follow-up she was very satisfied by the implant. She had significantly reduced use of pain control medications. She went back to her job, and she reported better social relationships.

\section{Case 4}

This 54-year-old woman presented with a 7-year history of left trigeminal neuralgia of uncertain origin. She was treated with alcoholization of the gasserian ganglion at another institution. Unfortunately her pain worsened after the procedure. As a consequence of incorrect alcohol injection, ulcerations and trophic changes appeared on the left hemiface along with vasomotor dysfunction, which was consistent with a complex regional pain syndrome Type II (Fig. 3A and B). She underwent implantation of an electrode covering the V2 area at the same institution, which was removed early because of infection. At admission to our department, the patient reported left facial pain in V1, V2, and V3 (VAS Score 10/10). Allodynia was prevalent in $\mathrm{V} 2$, and hyperalgesia was stronger in V3. At examination, dystrophic ulcerations covered the glabella, the left nasal ala, the left eyebrow, and the maxillary region. The patient was blind in the left eye, with no corneal reflex.

After a 14-day trial of PNFS in the V1, V2, and V3 regions, the patient underwent implantation of an octopolar electrode (Octad) in the left V3 region, and 2 quadripolar electrodes (Quad PISCES) in the left occipital and V2 regions that were connected to a pulse generator (Prime Advanced; all equipment obtained from Medtronic, Inc.), which was implanted in the left infraclavicular subcutaneous space (Fig. 3C). The implanted stimulator was programmed with a rate of $16 \mathrm{~Hz}$. Pulse width was set at 210 usec for V1, 350 usec for V2, and 370 usec for V3. The patient reported satisfactory pain relief (VAS Score 2/10). However, the system was removed 1 year later because of a Staphylococcus aureus infection that probably originated from her nasal septal ulcerations.
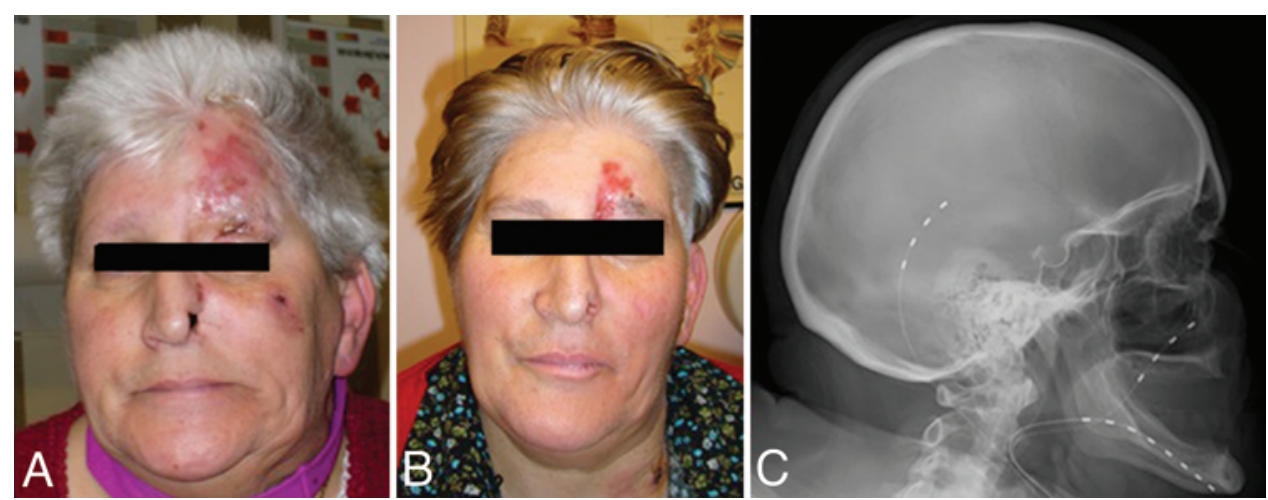

FIG. 3. Case 4. This patient presented with ulcerations and trophic changes of the left hemiface after alcohol injection into the gasserian ganglion (A). Pain and ulcerations improved (B) after implantation of an octopolar electrode in the left V3 region and 2 quadripolar electrodes in the left occipital and V2 regions. Postoperative radiograph (C) showing the implanted electrodes. 
Case 5

This 77-year-old woman presented with a 1-year history of postherpetic right trigeminal neuralgia in the V1 region. Standard medical treatments were not effective. The patient presented with V1 right trigeminal neuralgia (VAS Score 10/10). After the usual 14-day trial, the patient underwent implantation of 2 quadripolar electrodes (Quad PISCES) in the right V1 region, which were connected to a pulse generator (Prime Advanced; all equipment obtained from Medtronic, Inc.) that was implanted in the right infraclavicular subcutaneous space. The implanted stimulator was programmed with a pulse width of $450 \mu \mathrm{sec}$ and a rate of $50 \mathrm{~Hz}$. The patient reported satisfactory pain relief (VAS Score 3/10), which was confirmed at 2-year follow-up.

\section{Case 6}

This 67-year-old woman affected by rheumatoid arthritis presented with a long history of chronic facial pain in the V2 distribution of the right trigeminal nerve, rated $10 / 10$ on the VAS. A trigger point was identified at the emergence of the infraorbital nerve, which elicited local disregulation of the autonomic somatosensory system. Analgesic block of the left infraorbital nerve with local anesthetics was successful. A 21-day trial of PNS in the infraorbital nerve was successful, with a reported pain of 3/10 on the VAS (Fig. 4).

\section{Discussion}

Although the potential to control neuropathic pain with PNS was discovered by Wall and Sweet in the $1960 s,{ }^{30}$ this system was not commonly used in clinical practice until the late $1990 \mathrm{~s} .{ }^{31}$ Increasing interest about PNS and PNFS in recent years has led to a wider use of neurostimulation to control headache and pain in the extremities and in the occipital region. 1,7,9,11,14,17,21,22,25,28 Manufacturing developments have made it possible to reduce the thickness of the electrodes, which can also be used in facial regions without any esthetic impairment. A clear differential diagnosis between TNP and PIFP versus classic trigeminal neuralgia is mandatory to assess the proper treatment plan. Classic trigeminal neuralgia is characterized by severe attacks of electric-like pain, which are often triggered by a tactile stimulus. Patients are usually asymptomatic between attacks. Conversely, TNP or PIFP present with constant, continuous symptoms. The pathophysiology of TNP and PIFP is still poorly understood. In these cases, treatment can be particularly challenging because pain is resistant to the commonly used medications, and microvascular decompression and peripheral neurectomy are generally ineffective. We found 29 cases of TNP/PIFP treated with PNFS in the literature (Table 1). Trauma and herpes zoster are the most common causes. The supraorbital nerve is the most frequent target for trigeminal neurostimulation (22 cases), followed by the infraorbital nerve (10 cases). Reported results are good in the majority of the patients, with a pain reduction of at least $50 \%$ in more than $80 \%$ of cases. Follow-up times range from 3 months to 4 years. Besides infection, complications are usually related to mechanical issues such as electrode dislocation.

Our series includes 6 patients who underwent implantation of electrodes for supraorbital nerve (2), infraorbital nerve (4), occipital nerve (3), and mandibular nerve (1). In 2 patients more than one nerve was stimulated. The average VAS score at admission was 10 , whereas the average VAS score at the last follow-up was 2.7, confirming the high success rate of PNFS for TNP and PIFP (Table 2). Good outcome is dependent on correct patient selection. We applied the standard exclusion criteria that are also used for spinal cord stimulation..$^{18,19}$ Long-term anticoagulant therapy, earlier pacemaker implant, alcohol abuse, current medicolegal issues, and inadequate family compliance contraindicate PNFS surgery. Psychiatric disturbances such as personality alterations, active psychosis, and major depression were ruled out by administering the Minnesota Multiphasic Personality Inventory-2 test to all of our patients. Analgesic block of the affected nerves with local anesthetics was also useful in determining whether surgery is indicated.

Our surgical technique is similar to those already published and is performed in 2 steps. ${ }^{12,23}$ Initially, electrodes are inserted for the stimulation trial after induction of local anesthesia. We routinely insert the electrodes through a 3-mm supraauricular (V1 electrodes) or preauricular (V2 and V3 electrodes) vertical incision. A 14-gauge Tuohy needle is used to advance 4- or 8-contact electrodes percutaneously through a plane between the subcutaneous and dermal spaces (Fig. 5). The aim is to place the electrode at the level of the hyperalgesia strip, which is at the periphery of the allodynia region. In our experience this target allows the best pain control. We
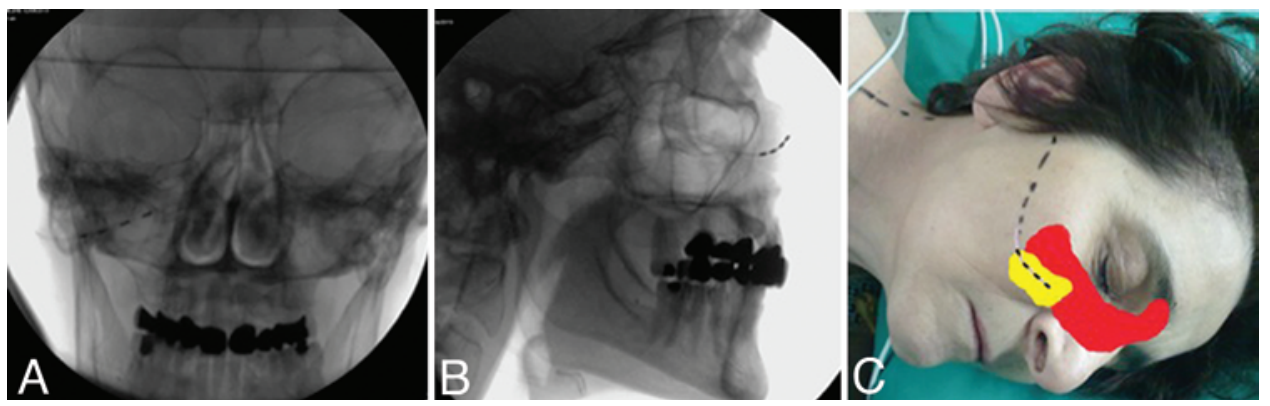

FIG. 4. Case 6. Frontal (A) and lateral (B) radiographs showing the placement of a quadripolar electrode in the right V2 region. Photograph (C) showing how the electrode (dotted lines) should be placed under the hyperalgesia strip (yellow), avoiding the allodynia region (red). 
Peripheral trigeminal nerve field stimulation

TABLE 1: Literature review of patients with permanent PNFS implants for TNP*

\begin{tabular}{|c|c|c|c|c|c|c|c|c|}
\hline Authors \& Year & $\begin{array}{l}\text { No. of } \\
\text { Pts }\end{array}$ & $\begin{array}{l}\text { Age (yrs) } \\
\text { Sex }\end{array}$ & Etiology & Area & Implant & FU & Outcome & Complications \\
\hline \multirow[t]{2}{*}{ Dunteman, 2002} & \multirow[t]{2}{*}{2} & $86, M$ & $\mathrm{PH}$ & It V1 & SON & \multirow[t]{2}{*}{3 yrs } & improved & \\
\hline & & $76, F$ & $\mathrm{PH}$ & It V1 & SON & & improved & battery exhaustion \\
\hline \multirow{10}{*}{$\begin{array}{l}\text { Johnson \& Burchiel, } \\
\quad 2004\end{array}$} & \multirow[t]{10}{*}{10} & $39, \mathrm{~F}$ & PT & rt V1 & SON & \multirow[t]{10}{*}{$2 \mathrm{yrs}$} & \multirow{10}{*}{$\begin{array}{l}70 \% \text { of pts } w />50 \% \\
\text { pain relief }\end{array}$} & wound breakdown \\
\hline & & $86, M$ & $\mathrm{PH}$ & $\mathrm{rt} \mathrm{V1}$ & SON & & & none \\
\hline & & $44, \mathrm{M}$ & $\mathrm{PH}$ & rt V1 & SON & & & none \\
\hline & & $37, \mathrm{~F}$ & AFP & It V1 & SON & & & wound breakdown \\
\hline & & $61, M$ & $\mathrm{PH}$ & It V1 & SON & & & short extension cable \\
\hline & & $41, M$ & PT & rt V1 & SON & & & none \\
\hline & & $83, \mathrm{~F}$ & $\mathrm{PH}$ & It V1 & SON & & & none \\
\hline & & $53, \mathrm{M}$ & PT & It V1 & SON & & & none \\
\hline & & $45, M$ & PT & It V2 & ION & & & none \\
\hline & & $33, \mathrm{M}$ & PT & $\mathrm{rt} \mathrm{V} 2$ & ION & & & none \\
\hline Slavin et al., 2006† & 9 & & & & $\begin{array}{c}\text { SON (4); ION (3); } \\
\text { ION + ON (1); } \\
\text { SON + ON (1) }\end{array}$ & 35 mos & $\begin{array}{l}73 \% \text { of pts } w />50 \% \\
\text { pain relief }\end{array}$ & \\
\hline Yakovlev \& Resch, 2010 & 1 & $72, \mathrm{~F}$ & AFP & It V3 & $\mathrm{MN}$ & 12 mos & excellent & \\
\hline \multirow[t]{3}{*}{ Stidd et al., 2012} & \multirow[t]{3}{*}{3} & $71, \mathrm{M}$ & PT & It V1, V2 & $\mathrm{SON}+\mathrm{ION}$ & 27 mos & VAS score from 10 to 0 & $\begin{array}{l}\text { occasional HA when stimu- } \\
\text { lator on \& no pain }\end{array}$ \\
\hline & & $52, \mathrm{M}$ & PT & It V1, V2 & $\mathrm{SON}+\mathrm{ION}$ & $23 \mathrm{mos}$ & VAS score from 8 to 0 & \\
\hline & & $44, \mathrm{M}$ & $\mathrm{PH}$ & $\mathrm{rt} \mathrm{V1}$ & SON (2 electrodes) & $6 \mathrm{mos}$ & $60 \%$ pain relief & dislocation of electrodes \\
\hline $\begin{array}{l}\text { Asensio-Samper et al., } \\
2008\end{array}$ & 1 & $34, \mathrm{M}$ & PT & rt V1 & SON & $4 \mathrm{yrs}$ & VAS score from 10 to 2 & $\begin{array}{l}\text { battery exhaustion } 4 \text { yrs } \\
\text { later }\end{array}$ \\
\hline Reverberi et al., 2009 & 1 & $61, F$ & ETN & rt V1, V2 & $\mathrm{SON}+\mathrm{ION}$ & $5 \mathrm{mos}$ & VAS score from 10 to 1 & dislocation of ION electrode \\
\hline Upadhyay et al., 2010 & 1 & & $\mathrm{PH}$ & V1 & SON & 8 wks & excellent & none \\
\hline Lenchig et al., 2012 & 1 & $42, F$ & PS & rt V1, V2 & $\mathrm{SON}+\mathrm{ION}$ & $3 \mathrm{mos}$ & $>50 \%$ pain relief & none \\
\hline
\end{tabular}

* AFP = atypical facial pain; ETN = essential trigeminal neuralgia; FU = follow-up; $\mathrm{HA}=$ headache; ION = infraorbital nerve; $\mathrm{MN}=$ mandibular nerve; ON = occipital nerve; $\mathrm{PH}=$ postherpetic; $\mathrm{PS}=$ postsurgical; $\mathrm{PT}=$ posttraumatic; pts = patients; $\mathrm{SON}=$ supraorbital nerve.

$\dagger$ Patients treated since 2000; data are the mean values referring to a wider series including occipital PNS.

hypothesize that in this way the electrode might stimulate A-beta fibers, which are closer to the hyperactivated $\mathrm{C}$-fibers in the hyperalgesia region. Further studies are required to verify this phenomenon.

Fluoroscopic guidance is used to verify the final position of the electrodes. The standard landmarks are used: the supraorbital foramen and ridge, the infraorbital foramen and ridge, the mandibular foramen, and the inion. The patient is intraoperatively tested for paresthesias induced by electrode stimulation to confirm the correct positioning. When inserting the electrode, the area of allodynia shouldn't be selected as the target area, because a complete deafferentation usually prevents any effect of PNFS or can even paradoxically enhance pain. Instead, the electrode should be positioned at the hyperalgesic peripheral area, where nerve connections are still present (Fig. 4C). We generally use a von Frey hair esthesiometer to map facial areas and identify both the allodynia region and the hyperalgesia strip. It is also advisable to avoid a position that is too close to the orbicularis oculi or the or-

TABLE 2: Patients treated with PNFS for TNP at Treviso Hospital

\begin{tabular}{|c|c|c|c|c|c|c|c|c|}
\hline \multirow{2}{*}{$\begin{array}{l}\text { Case } \\
\text { No. }\end{array}$} & \multirow{2}{*}{$\begin{array}{l}\text { Age (yrs), } \\
\text { Sex }\end{array}$} & \multirow[b]{2}{*}{ Etiology } & \multirow[b]{2}{*}{ Pain Region } & \multirow[b]{2}{*}{ Implant } & \multirow[b]{2}{*}{$\mathrm{FU}$ (mos) } & \multicolumn{2}{|c|}{ VAS } & \multirow[b]{2}{*}{ Complications } \\
\hline & & & & & & Preop & Postop & \\
\hline 1 & $22, \mathrm{~F}$ & PIFP & It V1, V2, ON & SON, ION, ON & 15 & 10 & 2 & none \\
\hline 2 & $58, M$ & PT & rt V1, ON & ON & 32 & 9 & 4 & none \\
\hline 3 & $41, \mathrm{~F}$ & PT & It > rt V2, V3 & ION & 19 & 10 & $0(\mathrm{It}), 5(\mathrm{rt})$ & traumatic rupture \\
\hline 4 & $54, \mathrm{~F}$ & PS (chemical) & It V1, V2, V3 & ON, ION, MN & 12 & 10 & 2 & infection \\
\hline 5 & $77, \mathrm{~F}$ & $\mathrm{PH}$ & rt V1 & SON & 24 & 10 & 3 & none \\
\hline 6 & $67, \mathrm{~F}$ & PIFP & rt V2 & ION & 1 & 10 & 3 & none \\
\hline
\end{tabular}




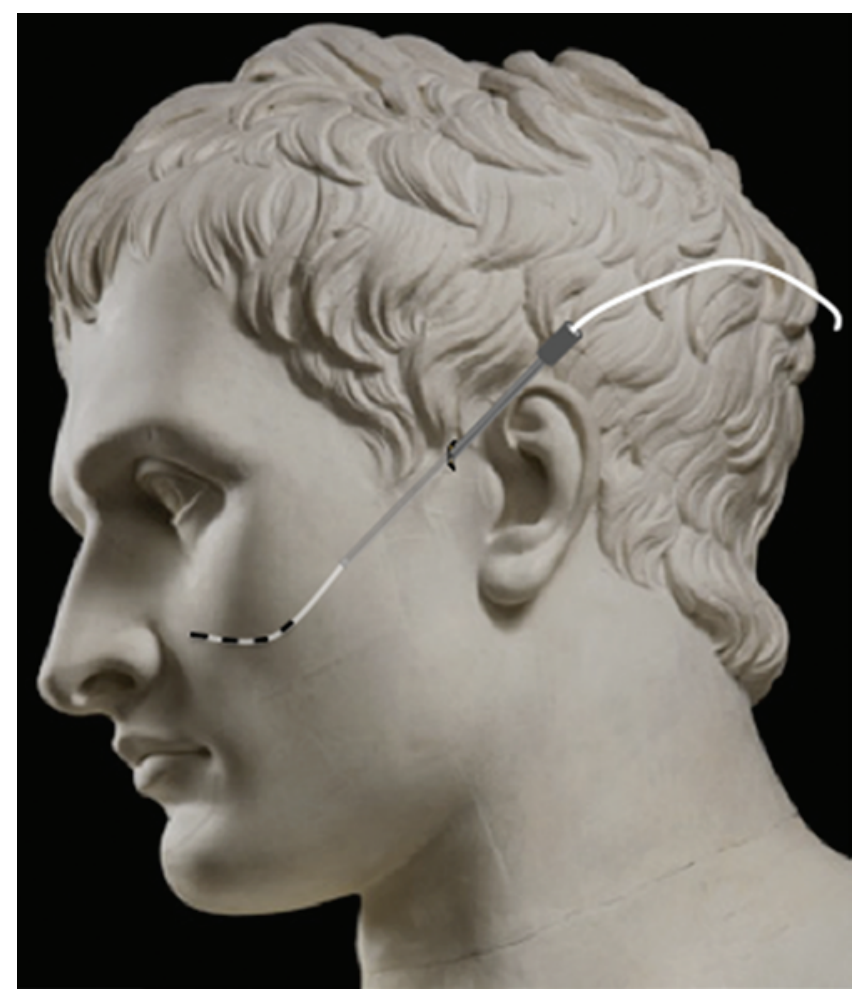

FIG. 5. The head of a statue of Napoleon by Antonio Canova is used to show how the electrode is advanced to the infraorbital region through a 14-gauge Tuohy needle.

bicularis oris muscles, to reduce the risk of direct muscle stimulation, with consequent uncontrolled spasms. The electrode is then tunneled to the retroauricular region, where it is secured with a stitch, and then to the shoulder, where it is sterilely covered and connected to the external stimulation system.

Displacement can be a complication when implanting electrodes, especially in the V3 distribution. Nonetheless, we think it is not advisable to secure the V3 lead in the mandibular region to avoid mechanical stress, which can potentially increase the risk of lead rupture. We prefer securing the electrode more proximally in the temporal retroauricular region. Because the cervical region is physiologically very mobile, forces applied to the catheter in this area may favor ruptures and dislocations. For this reason we always keep the catheter loose and longer than usual in the subcutaneous plane of the cervical region. The patient is instructed to adjust intensity of stimulation according to the level of pain. Prophylactic antibiotics are administered only during surgery. After trial completion, the temporary system is replaced by the permanent one. We use either quadripolar electrodes for V1 and V2 areas or octopolar electrodes for broader V3 and occipital areas. Sedation is induced during the tunneling of extension cables connecting the electrode with the generator and during the positioning of the generator. We usually implant the stimulator in the infraclavicular subcutaneous space. However, the axillary subcutaneous space is preferred in young women for esthetic purposes.

Case 3 is particularly interesting because the stimulation of the occipital nerves was able to significantly reduce not only the major occipital pain, but also the trigeminal pain. We noticed a similar effect also for the patient in Case 1, in whom 3 electrodes were implanted-on the supraorbital nerve, infraorbital nerve, and occipital nerve-and who reported enhanced trigeminal pain control when the occipital electrode was also activated. This effect can be explained by the presence of close relations between the pars caudalis of the spinal nucleus of the trigeminal nerve and the dorsal horn of the spinal cord. ${ }^{4,15,29}$ Increasing the rate of stimulation to $70-80 \mathrm{~Hz}$ can also enhance the backward stimulating effect. It is important to be aware of these anatomical interrelations, because they might sometimes be useful to increase the PNFSinduced pain control in patients affected by trigeminal neuralgia.

\section{Conclusions}

Peripheral nerve field stimulation for TNP and PIFP has a significant success rate, improving pain relief, functional capacity, and quality of life. The surgical procedure is relatively easy. However, a strict patient selection process is mandatory to rule out other causes of trigeminal pain. A careful patient examination is required to identify the hyperalgesia strip close to the allodynia region. This is the target area where electrodes should be positioned. Sometimes patients report both occipital and trigeminal pain. In other patients trigeminal PNFS alone has an incomplete effect on facial pain control. In such cases occipital stimulation can either fully control trigeminal pain or significantly enhance the effects of electrodes placed in the trigeminal nerve distribution. This is probably due to the trigeminocervical complex activation.

\section{Disclosure}

The authors report no conflict of interest concerning the materials or methods used in this study or the findings specified in this paper.

Author contributions to the study and manuscript preparation include the following. Conception and design: Feletti, Zanata Santi. Acquisition of data: Sammartino. Analysis and interpretation of data: Feletti, Zanata Santi. Drafting the article: Feletti. Critically revising the article: Zanata Santi, Sammartino, Bevilacqua, Cisotto, Longatti. Reviewed submitted version of manuscript: Feletti, Zanata Santi, Sammartino, Longatti. Approved the final version of the manuscript on behalf of all authors: Feletti. Statistical analysis: Feletti. Study supervision: Bevilacqua, Cisotto, Longatti.

\section{References}

1. Amin S, Buvanendran A, Park KS, Kroin JS, Moric M: Peripheral nerve stimulator for the treatment of supraorbital neuralgia: a retrospective case series. Cephalalgia 28:355-359, 2008

2. Asensio-Samper JM, Villanueva VL, Pérez AV, López MD, Monsalve V, Moliner S, et al: Peripheral neurostimulation in supraorbital neuralgia refractory to conventional therapy. Pain Pract 8:120-124, 2008

3. Barolat G: Peripheral Subcutaneous Stimulation. A Photographic Surgical Atlas. Denver, CO: Barolat Institute, 2009

4. Bogduk N: Anatomy and physiology of headache. Biomed Pharmacother 49:435-445, 1995

5. Dunteman E: Peripheral nerve stimulation for unremitting 
ophthalmic postherpetic neuralgia. Neuromodulation 5:3237, 2002

6. Dworkin RH: An overview of neuropathic pain: syndromes, symptoms, signs, and several mechanisms. Clin J Pain 18: 343-349, 2002

7. Hassenbusch SJ, Stanton-Hicks M, Schoppa D, Walsh JG, Covington EC: Long-term results of peripheral nerve stimulation for reflex sympathetic dystrophy. J Neurosurg 84:415423, 1996

8. Headache Classification Subcommittee of the International Headache Society: The International Classification of Headache Disorders: 2nd edition. Cephalgia 24 Suppl 1:9-160, 2004

9. Heavner JE, Racz GB, Diede JM: Peripheral nerve stimulation: current concepts, in Waldman SD, Winnie AP (eds): Interventional Pain Management. Philadelphia: WB Saunders, 1996, pp 423-425

10. International Association for the Study of Pain: Trigeminal neuralgia and persistent idiopathic facial pain. (http:// www.iasp-pain.org/AM/Template.cfm?Section=Fact_Sheets $4 \&$ Template $=/ \mathrm{CM} /$ ContentDisplay.cfm \&ContentID $=14459$ ) [Accessed July 22, 2013]

11. Jasper JF, Hayek SM: Implanted occipital nerve stimulators. Pain Physician 11:187-200, 2008

12. Johnson MD, Burchiel KJ: Peripheral stimulation for treatment of trigeminal postherpetic neuralgia and trigeminal posttraumatic neuropathic pain: a pilot study. Neurosurgery 55: 135-142, 2004

13. Lenchig S, Cohen J, Patin D: A minimally invasive surgical technique for the treatment of posttraumatic trigeminal neuropathic pain with peripheral nerve stimulation. Pain Physician 15:E725-E732, 2012

14. Magis D, Allena M, Bolla M, De Pasqua V, Remacle JM, Schoenen J: Occipital nerve stimulation for drug-resistant chronic cluster headache: a prospective pilot study. Lancet Neurol 6:314-321, 2007

15. Matharu MS, Bartsch T, Ward N, Frackowiak RS, Weiner R, Goadsby PJ: Central neuromodulation in chronic migraine patients with suboccipital stimulators: a PET study. Brain 127: 220-230, 2004

16. Meyerson BA, Lindblom U, Linderoth B, Lind G, Herregodts $\mathrm{P}$ : Motor cortex stimulation as treatment of trigeminal neuropathic pain. Acta Neurochir Suppl (Wien) 58:150-153, 1993

17. Mobbs RJ, Nair S, Blum P: Peripheral nerve stimulation for the treatment of chronic pain. J Clin Neurosci 14:216-223, 2007

18. North RB, Kidd DH, Olin J, Sieracki JM, Boulay M: Spinal cord stimulation with interleaved pulses: a randomized, controlled trial. Neuromodulation 10:349-357, 2007

19. Oakley J, Varga C, Krames E, Bradley K: Real-time paresthesia steering using continuous electric field adjustment. Part
I: Intraoperative performance. Neuromodulation 7:157-167, 2004

20. Piedimonte F, Schvarcz JR: Stereotactic trigeminal nucleotomy for dysesthetic facial pain. Stereotact Funct Neurosurg 68:175-181, 1997

21. Reed KL: Peripheral neuromodulation and headaches: history, clinical approach, and considerations on underlying mechanisms. Curr Pain Headache Rep 17:305, 2013

22. Reverberi C, Bonezzi C, Demartini L: Peripheral subcutaneous neurostimulation in the management of neuropathic pain: five case reports. Neuromodulation 12:146-155, 2009

23. Slavin KV: Peripheral nerve stimulation for neuropathic pain. Neurotherapeutics 5:100-106, 2008

24. Slavin KV, Colpan ME, Munawar N, Wess C, Nersesyan H: Trigeminal and occipital peripheral nerve stimulation for craniofacial pain: a single-institution experience and review of the literature. Neurosurg Focus 21(6):E5, 2006

25. Stanton-Hicks M, Salamon J: Stimulation of the central and peripheral nervous system for the control of pain. J Clin Neurophysiol 14:46-62, 1997

26. Stidd DA, Wuollet AL, Bowden K, Price T, Patwardhan A, Barker S, et al: Peripheral nerve stimulation for trigeminal neuropathic pain. Pain Physician 15:27-33, 2012

27. Upadhyay SP, Rana SP, Mishra S, Bhatnagar S: Successful treatment of an intractable postherpetic neuralgia (PHN) using peripheral nerve field stimulation (PNFS). Am J Hosp Palliat Care 27:59-62, 2010

28. Urban BJ, Nashold BS Jr: Combined epidural and peripheral nerve stimulation for relief of pain. Description of technique and preliminary results. J Neurosurg 57:365-369, 1982

29. Van Buyten JP, Linderoth B: Invasive neurostimulation in facial pain and headache syndromes. Eur J Pain Suppl 5:409421, 2011

30. Wall PD, Sweet WH: Temporary abolition of pain in man. Science 155:108-109, 1967

31. Weiner RL, Reed KL: Peripheral neurostimulation for control of intractable occipital neuralgia. Neuromodulation 2:217221, 1999

32. Yakovlev AE, Resch BE: Treatment of chronic intractable atypical facial pain using peripheral subcutaneous field stimulation. Neuromodulation 13:137-140, 2010

Manuscript submitted May 14, 2013.

Accepted July 3, 2013.

Please include this information when citing this paper: DOI: 10.3171/2013.7.FOCUS13228.

Address correspondence to: Alberto Feletti, M.D., Ph.D., Department of Neurosurgery, Treviso Hospital, University of Padova, Piazza Ospedale 1, 31100 Treviso, Italy. email: alberto.feletti@ gmail.com. 